\title{
Active Interview Tactics Revisited: A Multigenerational Perspective
}

\author{
Andrew D. Hathaway \\ University of Guelph, Canada
}

Rory Sommers

Sheridan College, Canada

\author{
Amir Mostaghim \\ University of Ontario Institute of Technology, Canada
}

DOI: http://dx.doi.org/10.18778/1733-8077.16.2.09

Keywords:

Active Interviewing;

Self-Presentation;

Reflexivity

\begin{abstract}
William (Billy) Shaffir taught about what it means to be a true empiricist, a sociologist committed to naturalistic observation as the most incisive method in our scientific toolbox. His inspiration still resonates, two decades later, in the work of new emerging scholars with the same commitment to ethnography-or what Billy more modestly and wisely calls "hanging around." This paper is a tribute to his legacy that highlights the contributions of the next generation of graduate students that the lead author has been privileged to mentor at the University of Guelph. It builds on work by Hathaway and Atkinson on tactics of active interviewing to establish a more nuanced understanding of the benefits and challenges of being recognized as either an "insider" or "outsider," and the implications of attempting to be both.
\end{abstract}

Andrew Hathaway is an Associate Professor who teaches in the Department of Sociology \& Anthropology at the University of Guelph. He has studied drug use and drug policy in Canada using surveys, interviews, and ethnographic methods. His contributions to the literature on active interviewing have been previously published in the journal Field Methods and The SAGE Encyclopedia of Research Methods.

email address: hathawaa@uoguelph.ca

Rory Sommers teaches criminology in the Faculty of Humanities \& Social Sciences at Sheridan College in Ontario, Canada. He completed his PhD in sociology in 2016 at the
University of Guelph. His ethnographic research examined policies and practice of municipal law enforcement in Hamilton, Ontario.

email address: Rory.sommers@sheridancollege.ca

Amir Mostaghim is an Associate Teaching Professor in the Faculty of Social Science and Humanities at the University of Ontario Institute of Technology. He completed his PhD in sociology in 2019 at the University of Guelph. His research focused on perceptions and experiences of cannabis use among undergraduate students.

email address: amir.moghastim@uoit.ca 


\section{Prologue}

The first author is a former student of William Shaffir's at McMaster University (PhD, 2000) and Robert Stebbins at the University of Calgary (MA, 1995). In their book, Experiencing Fieldwork (Shaffir and Stebbins 1990), they observe that sociological field research is typically conducted on cultural phenomena within one's own society. As such, the group or institution being studied is embedded in a network of social relations of which the investigator as observer is an integral part. When people are aware of being observed, they ordinarily strive to make a good impression. Research subjects emphasize one of several selves that they deem appropriate in the observer's presence.

Self-presentation on the part of the observer is no less salient, and fraught with implications for research. Maintaining neutral rationality when emotion is expected reinforces expectations that the observer is just that: only an observer to be treated as such. More penetrating or investigative research methods are needed to gain access to more private spheres of life. Ethnographers are well advised to be especially attentive when people relax their guard (Shaffir 1999). Studying human behavior in natural settings also requires some measure of role-playing and self-presentation that cannot be fully calculated in advance. Self-presentation work evolves throughout the research process.

As a former student of Malcolm Spector, Shaffir recognized that better understanding social phenomena requires uncovering how actors define the situation and interpret their reality. The "bottom line" in ethnographic research is, put otherwise, the pursuit of a clearer and sharper understanding of human lived experience. Respecting the inevitable bound- aries between research subjects and researchers need not detract from fieldwork. Shaffir's reflections on entering the field and self-presentation in his work on Jewish Orthodox communities highlight the often-unexpected uniqueness of each setting.

The social skills and circumstances of the researcher, regardless, tend to override professional claims about our research and determine the particular fieldwork strategies employed. Shaffir (1990) observes that although many research participants are more than willing to talk about themselves, many are also (understandably) indifferent about taking part in research of little relevance to them. Gaining some level of acceptance is essential, requiring the researcher to present a particular image to be granted access and secure cooperation. The proffered image cannot always be determined in advance, dependent as it is on the adoption of a role that reflects multiple contingencies encountered in the field.

Whereas the roles assumed evolve throughout the research process, the true measure of the value of any given role is the vantage point provided to the participant who plays it. Deception is inherent in the sense that the ethnographer is always more observer than participant, and is especially observant of what happens when the observed let down their guard. Deceit is largely unavoidable, since it is rarely wise or manageable to share all our research interests with the people that we study. But, overt deception is unethical; moreover, it is often difficult to execute in practice.

Rather than attempting to manipulate informants, Shaffir's experiences suggest that fieldworkers try to be as up-front as possible about their research interests. He notes that both our research aims and self-presentation strategies are shaped by the par- 
ticipants with whom we interact. The roles we play are influenced as much at times by our own personal commitments and considerations as they are by academic interests and concerns. Attempting to display a particular image that the researcher interprets will be received favorably requires projecting personal and academic interests.

Formal introductions of credentials and objectives tend to matter less than explanations that group members develop to account for the appearance of a stranger who is eager to observe and understand their way of life. The role and status of the researcher are not so much assumed as assigned by others in a manner that reflects their own understanding of the outsider's presence. Academic credentials are ordinarily outweighed by personal(ity) traits conducive to being granted access and cooperation of the group. Downplaying academic status and vocabulary is also recommended to facilitate exchanges that ideally take the form of a casual conversation.

Pretending to know less about a conversation topic is a deceptive practice that falls short of outright lying and is as commonplace in research as it is in daily life. If our goal is to develop a better understanding of human lived experience, it stands to reason that the sharpest tools at our disposal are those linked to sociability and the ways we are perceived as ordinary human beings. In Shaffir's (1998:48) words: “The extent to which we are seen as likeable, friendly, dependable, and honest bears directly on our ability to collect rich and deep data with which to better understand and analyze the social world under study."

On having gained admission to a social circle or set of activities, convincing and persuasive self-presentation tactics are at the heart of the art of field research throughout one's time remaining in the field. The research subject's understanding of the objectives of the study is more of a response to the researcher's human qualities, or how we are perceived, than to its scientific merits. Success in fieldwork is primarily determined by the performance of interactional skills that set the stage for the development and nurturing of relationships. Field research is accordingly more art or craft than science, being learned experientially rather than by formal training on research protocols for executing standardized procedures.

Pursuing intimate familiarity in fieldwork calls for more explicit recognition by researchers that we occupy several statuses simultaneously. The researcher role need not always predominate. Shaffir (1998) observes that some of his best insights came to light only after telling people more about himself. More important than obsessing about scientific methods is the need for sociability in attending to the human demands that shape relationships, and being open to exchanges that allow others to become familiar with our non-academic selves. Eschewing the obsession with collecting the "right data" in favor of more natural conversational dynamics frees us to inject our views and challenge those of others in ways that make for interesting and lively exchanges.

Acquiring the most credible and deep appreciation of human lived reality through social interaction requires that we immerse ourselves in the social worlds of others. In so doing, field researchers seek to cultivate relationships that grant us access to data we may not otherwise be privy to. Yet, despite the benefits of instrumental membership, we can never be true insiders. In the spirit of having more open and honest discussions about practices of ethnographic research, Shaffir's personal reflections of experiences in fieldwork illustrate the boundaries to 
full participation that prevent us from abandoning our status as observers.

\section{Introduction}

Effective and strategic self-presentation is essential for establishing relationships that enable us to navigate the advantages and disadvantages of pursuing more or less attached ethnographic points of view. The foregoing insights on ethnography are equally germane to interviewing, which is observed to have become the primary source of data in the social sciences (cf. Briggs 1986; Hammersley 2003; Atkinson and Delamont 2006). There is arguably a tendency to overly romanticize the insights gained from interviews as being more "authentic" than data gathered using other methods (Atkinson and Silverman 1997). Other critics argue that there has been too much emphasis on designing protocols with overly prescriptive schedules to ensure that interviews are "well-conducted" (Holstein and Gubrium 2016; Silverman 2017).

The resulting call for more creative use of interviews is by no means new (cf. Carey 1972; Miller and Tewksbury 2001). The literature on active interviewing is explicitly concerned with documenting and reflecting on new strategies for producing more revealing data. Active interviewing departs from standardized approaches by treating the participants as meaning co-creators (Holstein and Gubrium 1995). Self-presentations shape the narrative by (re)positioning respondents in relation to each other as the interview unfolds. In anticipation and reaction to the other, participants employ conducive narrative resources.

Interviewers draw on background knowledge and shared experience to build rapport with interviewees, as well as to establish and interpret themes emerging in the data. The aim is not to coax pre- ferred responses, but instead facilitate an interactive dialogue that more closely resembles everyday conversation than a formal interview. The interviewer may introduce competing narratives in order to elicit a response that undermines or deviates from the interviewee's previous account. The ensuing interaction between interview participants has been characterized as an unscripted interpersonal drama that neither of the actors can prepare for in advance (Holstein and Gubrium 1995).

From a constructionist perspective, the interview is understood as a social interaction or occasion where the dialogue is a social product of negotiation (Briggs 1986; Hammersley 2003). Interviews are forums for claims making (Spector 1980) that facilitate unstructured, open-ended talk as a performative event (Holstein and Gubrium 1995). Viewing interview exchanges as performances means bringing "heterogeneous stylistic resources, context-sensitive meanings, and conflicting ideologies into the reflexive arena where they can be examined critically" (Bauman and Briggs 1990:60).

Conducting active interviews provides an opportunity to better understand and draw upon the contextually embedded discourses or "social poetics" (Clifford and Marcus 1986) of the situation or subject under study. The "strange" and the "familiar" are subjected to greater scrutiny due to the cultural intimacy invoked by interview participants interacting from positions of commonality and difference. The quality of ethnographic research is often measured by the ethnographer's ability to gain access to the "backstage" (Goffman 1959) of the social practice or setting being studied.

It has been noted that informants often make a conscious effort to conceal the back regions researchers 
seek to access (Berreman 1962). In this vein, conflict methodologists go further in asserting that research participants are deliberately deceptive (cf. Lundman and McFarlane 1974; Christie 1976; Young 1976; Adler, Adler, and Rochford 1986). More in line with Becker's (1970) observations on the matter, the primary concern of the active interviewer is striving not to be too overly accommodating of the accounts of interview participants (see also Douglas 1985).

\section{Exploring the Continuum of Tactical Engagement}

Active interviewers seek to critically examine interviewee's narratives while attempting to uncover perspectives that have not yet been disclosed. Hathaway and Atkinson (2003; 2005) envisioned a continuum of tactical engagement that can be drawn upon when doing qualitative interviews. Rapport is needed to gain trust and issue challenges to stimulate deeper narrative accounts. Invoking the personas of the "good cop" and the "bad cop," the initial stages of the interview are characterized as social lubricants to foster a greater exchange of information (see also Weiss 1994; Dewalt and Dewalt 1998).

In the early going, the interviewer is advised to use familiar terms based on prior knowledge and experience to establish trust that sets the stage for more aggressive and challenging lines of inquiry. By building on more passive, neutral styles of interviewing, a fuller range of tactics can be mobilized to include more pressing, provocative conversational strategies. Becker (1954) noted long ago that seeming to be skeptical or "playing dumb" about facts that were taken-for-granted can be used to elicit more candid responses (see also Hermanowicz 2002; McLuhan, this volume).
Whereas transforming into "bad cop" may not be advisable or feasible, less confrontational tactics like Becker's are indispensable for provoking fuller or alternative accounts. Returning to revisit and re-evaluate prior claims is another strategy he commonly employed. At every level of engagement there are both well-known and unknown risks that may inhibit the flow of interaction and the exchange of information. Impression management inevitably is part of the performance and contingent on the participants' presentation of self. The research literature on active interviewing is evolving, due to a need for more reflection on the intersecting ways that reflexivity, power dynamics, and positionality converge to shape the narratives produced.

\section{Unpacking Power, Reflexivity, and Positionality}

A concern for reflexivity emerged from feminist critiques of the neglect of power dynamics operating during interviews (cf. England 1994; Mauthner and Doucet 2003; Day 2012). Interviewers and interviewees are necessarily reflexive. The influence of power and reflexivity cannot only be considered retrospectively, but also during "real time" (Weick 2002) or "in the moment" (Riach 2009) during interviews. That requires awareness of the dominant discourses that shape the narratives produced, and openness to viewing interview performances from multiple perspectives. The narratives produced are shaped by the positionalities of interview participants within their social circumstances. The interviewer must, accordingly, strategically adapt in view of shared experiences and social differences that influence the active interview performance. The unfolding dialogue is not only a reflection, but also (re)produces the existing power relations (Aléx and Hammarström 2008). 
The power-resistance dynamic is conceptualized as being somewhat fluid because participants might occupy positions of dominance and inferiority at different times. The narratives produced are open to interpretation through a myriad of shifting power positions that are adopted, imposed, and resisted by the interview participants. Positionalities reflect one's socio-economic status, occupation, education, gender, age, ethnicity, among other intersecting social characteristics. These positionalities shape interview exchanges (see also Song and Parker 1995); and the ways they intersect are often shifting and unstable. It is possible to occupy shifting positionalities by acting more or less attached at different junctures of the interview. At the same time, conversation and disclosure can be disrupted by participants adopting "wrong" positions (Aléx and Hammarström 2008). These same "sticky moments" (Riach 2009) demonstrating lack-of-fit present new opportunities to study reflexivity.

The "insider" versus "outsider" dichotomy oversimplifies the complexity of social interaction during interviews. Interviewers, like ethnographers, are never fully either insiders or outsiders in relation to the other. The unfolding interpersonal drama is unpredictable. The plot and role of positionalities, and resulting opportunities, cannot be entirely anticipated in advance. The reflexive nature of active interviewing introduces inconsistencies in how participants interpret commonality and difference. Self-disclosure, for example, has both advantages and risks. As a strategy for making interviewees feel safer (see Song and Parker1995)-and eliciting candor about sensitive matters-it can also make participants more hesitant or guarded, when it serves to highlight social differences instead. At the same time, sometimes acting more detached from interviewees can lead to fuller disclosure (Abell et al. 2006).
The present paper builds on observations by Shaffir (1990; 1998; 1999) and literature on active interviewing to establish a more nuanced understanding of the benefits and challenges of being recognized as either an insider or outsider and the implications of attempting to be both. We draw on illustrations from the interviews conducted by the two coauthors for their doctoral research projects.

\section{The Studies}

Mostaghim (2019) conducted interviews with undergraduate students at the University of Guelph as part of the lead author's three-campus study of experiences and attitudes towards the use of cannabis (see: Hathaway et al. 2016; 2018). The interviewer's characteristics and positionality-as an Iranian male who used cannabis, and was in his late 20s at the time of the studywere noted to both hinder and facilitate responses, requiring flexibility in his use of probing tactics. Student attitudes and experiences, as users and non-users, were found to vary widely by ethnicity and gender.

The patterned variation of responses often followed exchanges in which interviewee's statements had alluded to common traits or differences with the interviewer. Use of the term "you know" (or "you don't know"), in particular, featured in exchanges in which responses served as cues that the interviewer had been positioned in a way that reinforced his "insider" or "outsider" status. Male students from the Middle East and Southeast Asia, for example, often used the term "you know" to indicate familiarity with common cultural understandings about the use of drugs.

\section{What to Do with "You Know" / "You Don't Know"}

Being granted status as a cultural insider sometimes helps and sometimes hinders. It proved useful in 
some interviews, to overcome self-censoring or a reluctance to elaborate, for the interviewer to share his own experiences as someone who was raised in the Iranian community. Anti-western views in some ethnic communities are aligned with stereotypes of marijuana use as a symbol of overly westernized youth. The interviewer's status as a visible minority facilitated probing into these issues by establishing rapport.

Interviewees seemed more open to discussing ethnic stereotypes with a cultural insider than they might otherwise have been. Shared understandings granted access to more sensitive subject matter, such as parents' attitudes towards the use of drugs. Ethnic students seemed more open to discussing their experiences following exchanges in which the interviewer was able to assure them that he understood their parents were not "stereotypically conservative," but merely culturally conventional in upholding rigid standards that prohibit marijuana use.

Insider status hindered interaction in some interviews, at times, when the assumed familiarity with ethnic attitudes impeded deeper probing of "brown cultures." When asked if he would ever date a marijuana user, a male student from India, for example, laughed and stated: "You know how it is. You are brown yourself." Adherence to traditional gender roles, which stigmatize marijuana use by females relatively severely, thereby went unspoken. As something "everybody knows" (if they are cultural insiders), such knowledge is typically taken-for-granted (see: Garfinkel 1984).

In such instances, the strategy of "playing dumb" was called on to facilitate vocalization of cultural narratives impeded by "shared understandings." The following exchange is an example illustrating the need to feign naivety at times to prompt explic- it conversation about norms in ethnic families and communities. Another interviewee stated:

My parents aren't controlling, they just want what they think is right-you know what I mean?

[I am not sure. Can you elaborate?]

It's hard; like white people think that my parents are conservative and are like, you know, stereotypical brown parents. But, they are not; they just have their ways, you know? Like, you know how it is...they have their own point of view and they want me to respect that, unless I can convince them otherwise.

Expressing skepticism is another tactic that proved useful during interviews. When asked why they do not use marijuana, for example, some students remarked that "you know, it's not a brown thing" or "it's more of a white thing" to do. When challenged, by referring to the fact that some "brown people" do use marijuana, one Indian student clarified his statement by asserting that "it is the coconuts who smoke weed." Put otherwise, it is a sign of westernized behavior, by someone who appears brown but is white on the inside.

More generally, a non-judgmental tone proved most effective for navigating challenges and opportunities provided by the interviewer's inside and/or outside status. Overt differences observed in the experiences and attitudes of female interviewees cued a need for different tactics to probe beyond assertions like "you wouldn't understand" or "you don't know how it is." During interviews with non-users, whether male or female, they often seemed defensive for choosing not to use when so many of their peers are marijuana users.

Non-users sometimes prefaced their remarks by stating that they have no objection to using marijuana, or 
that views of users are more important to the study. Such responses called for reassurances that their experiences and attitudes were equally important for the research, and that other interviewees had shared similar opinions. At times of hesitation, for apparent fear of judgment, assuring interview participants that their attitudes were not unimportant or unusual gave them "permission" to more fully share their views.

In interviews with students who were marijuana users, self-disclosure by the interviewer was another form of sharing that proved useful to establish trust, alleviating fear of judgment. Some cues that prompted self-disclosure of the interviewer's status as a fellow user included the prefacing of statements with "I am not a pot-head" and/or "I am agood student." One must be cautious not to "over-share" or overshadow the interviewee's narrative by imposing one suggested by the interviewer. However, self-disclosure is a tactic that can help facilitate a non-judgmental tone.

Claiming status as a (sub)cultural insider, or having it ascribed to us as interviewers might also lead to "sticky" situations during interviews that can be both risky and revealing. Engaging with white students about ethnicity was often difficult, evoking "you know" statements that required a non-judgmental tone that gave them permission to be candid. One white student was asked, for example: "Why do you think brown people are less likely to be users?" He replied: "Well, you know, how it is man. Like they care about image and stuff a lot more." [Can you tell me more?] "You know, man. Like I am not sure about you, but, you know, most of my brown friends are really into what their family thinks of them and stuff."

Another white student responded that Asian parents are less likely to allow youth to have fun. "You must know what I'm talking about," he continued, "because you are brown as well." When challenged with a skeptical reply, the interviewee assured the interviewer that he "wasn't being racist" and asserted he would rather not discuss the matter further. Sensitivities surrounding race and gender thereby offer opportunities for probing based on presumed positionality; but interviewers must be cautious. Giving interview participants permission to be candid can, at times, seem threatening and disrupt the interview by counteracting efforts to establish rapport. To demonstrate the broader relevance of the foregoing observations during interviews with students, we turn to illustrations from a different kind of study. The experiences of the interviewer in our second study offer further insights into the benefits and challenges of being identified as an "insider" or "outsider" and what one stands to gain by seeking to be both.

\section{Interviewing City Planners and Officials}

Sommers' (2016) study of municipal law enforcement practices in Hamilton, Ontario involved ethnographic observation (600+ hours of "ride-alongs") with officers and twenty interviews with city planners and officials. The focus of the fieldwork was examining the practice of municipal law enforcement in the context of official priorities which called for a proactive, "zero-tolerance" approach. In practice, it was found that law enforcement was primarily reactive, not proactive, and concerned with management of conflicts arising between neighbors and assuring public safety-rather than addressing signs of physical decay and social disorder in the downtown core.

Conducting interviews with city planners and officials provided opportunities to better understand 
the observed gap between municipal policy and practice on the matter of bylaw enforcement. The interviewer's fieldwork afforded him some inside status as an informed observer, which proved useful when discussing politically sensitive matters. Attempts to dodge contentious issues like displacing homeless people from illegal dwellings, for example, included common references by interviewees to the "City's official position."

Moving past stock phrases that signified a "closing off" (Keating 1993) of critical inquiry was achieved by drawing on experiences in fieldwork, such as when it was observed that the displacement/relocation was due to safety issues that were in the interests of all parties to resolve. The interviewer's sharing of experiences thereby gave the interviewee the permission to speak more openly and candidly about difficult decisions and "grey areas" of law.

Interviewing city planners, whose work was more removed from the policy and practice of municipal law enforcement, also sometimes called for tactics in which insights gained from fieldwork proved useful in establishing rapport. Eliciting more candor in some cases was achieved by directly challenging responses that appeared to be rehearsed. For example:

[Could you describe what is meant by a "get tough approach" to municipal law enforcement in the City?] Our policy documents are quite clear...our get tough or zero-tolerance approach, whatever you want to call it...people throughout the City need to get the message...it's about improving the City's image.

[Having spent some time observing the enforcement of municipal law, it seems officers use a great deal of discretion...In fact, somewhat contrary to a "get tough approach" officers seem very willing to work with residents-especially in lower income areas of the City.]

Well, perhaps some of what has been written in City documents comes off as a little more aggressive than what unfolds on the frontlines...While I support what is outlined in our planning documents, I guess it's somewhat unspoken that officers use discretion, especially when dealing with vulnerable populations.

There are evidently limits to adopting more "aggressive" strategies relying on experiential knowledge. To illustrate, the following exchange is an example wherein the interviewee (a municipal law official) rejects the interviewer's inside knowledge as inadequate for understanding the bigger picture in which certain "unofficial" enforcement practices occur. The attempt to draw on insights gained from the fieldwork in this interview resulted in denial and abruptly closing off the line of inquiry:

[During my time in the field, officers discussed how they were encouraged to ticket and add fees for services when attending a certain downtown hotel. It was suggested to me on several occasions that these added fees would pressure the owners to sell the property.] You mean Motor City?

[Yes, Motor City.]

Well, I'm not sure why any officers would tell you that.

[It wasn't just officers. I've also attended several public meetings that discussed how a zero-tolerance approach was being used on that specific property.]

I know you've been at this [research] for months, but what's happened recently at Motor City is only part of the story...I suggest you look into the decade of problems there...

[I understand...when exactly did the problems start at Motor City?]

I think I've said all I want to say...I'd like to move on. 
At other times, for different reasons, the interviewer's fieldwork evidently hindered the exchange of information during interviews. Responses prefaced with common phrases like "as you know," "as you saw with the officers," and "as you experienced" were often preemptive of more detailed answers. Being granted status as an insider presented distinctive challenges when trying to adopt a more detached or neutral style of questioning in interviews.

Once insider status is conferred on interviewers, transitioning to the use of other tactics can be difficult. This is illustrated in the following exchange which required the interviewer, after several attempts to adopt an "uninformed" view, to assume the stance of an insider:

[What makes regulating the taxi industry in Hamilton so challenging?]

I think you know the answer...you've seen it firsthand, haven't you?

[I am wondering if you could discuss the challenges from more of a planning/licensing standpoint?]

Well...I think the guys enforcing on taxis probably have a more accurate idea of what's wrong with the industry.

[That's fair. However, I am wondering if this is something that the City could address through initiatives that start in the planning department?]

I am hesitant to go any further because I am not sure how much our official policies are helping the guys [officers)] dealing with taxis...you know the laws; you know what happens out there.

[Okay then. My time in the field would suggest that only a limited amount of officers are dedicated to taxi enforcement. Can we talk about resources and funding more officers?]

At other times, downplaying inside knowledge ("playing dumb") to stimulate disclosure was suc- cessful. The complexity and scope and high number of ongoing investigations observed during fieldwork made downplaying these understandings seem honest and credible. This tactic proved to be particularly useful in interviews with city planners.

In the following example, playing dumb resulted in disclosure that exemplified the gap between "priorities" and practice with regard to the commitment to democratizing access by holding public meetings to identify local needs. The interviewer asked if issues raised at public meetings were likely to be given equal consideration. The city planner replied:

You know how it goes in these meetings. It's probably no different for the bylaw guys. We [the planning department] have to prioritize what's important and what is not.

[My study focused primarily on the enforcement side of things.]

There is only a handful of people who show up to these meetings and often what they see as a problem in their neighborhood has little to do with our longterm vision.

[So why does the City bother having these meetings if the people who show up don't really represent the whole neighborhood?]

In some cases these meetings do help us identify issues, but in others we [the City] really don't get much from them.

[So what you're saying is some public consultations have little impact on funding?]

You got it. But, we [the City] can say that we did have a consult.

In sum, these illustrations further demonstrate the various opportunities and challenges of having inside knowledge. In preparing for the study, the interviewer's research training might contribute 
to developing awareness of potential outcomes of adopting a particular persona or self-presentation strategy. It must also be acknowledged that the fuller implications of being cast as either an insider or outsider (or both) cannot be fully anticipated in advance.

Elastic reflexivity in positionality has evident advantages, prompting critical exchanges that have the potential to result in richer data (see also Moss 1995; Herod 1999; Rice 2010).Transitioning can also hinder exchanges moving forward and inhibit opportunities for further repositioning, once the interviewer is identified as having either an insider's or outsider's status.

\section{Discussion}

This paper builds on observations by Shaffir on self-presentation in ethnographic fieldwork. As a doctoral student of Shaffir's, the lead author's approach to interviewing was informed by this and earlier work by Malcolm Spector on researching public figures. The focus of the present work builds on these contributions further by providing illustrations from the research of two recent $\mathrm{PhDs}$ at the University of Guelph. The collaboration demonstrates the value of pursuing a multi-generational perspective on research methods that draws on the experiences of established and emerging scholars. The result is a more nuanced and developed understanding of the advantages and challenges associated with adopting a reflexive approach to interviewing.

Arguably, all qualitative methods share a similar commitment to employing naturalistic observation. But, active interviewing treats participants explicitly as meaning co-creators to produce insightful data. Interview participants shape the emerging narrative by (re)positioning and being (re)positioned in relation to the other throughout the interview. Sharing background knowledge and experience are narrative resources employed by interviewers to establish a rapport that is conducive to developing an interactive dialogue resembling the back and forth of open-ended talk.

Conducting active interviews provides an opportunity to better understand both the "strange" and the "familiar" through interaction premised on a natural conversation. Social interaction between interview participants is enacted from positions of sameness and difference reflecting relative "insider" and "outsider" points of view. Regardless of positioning, as the interview unfolds, the primary concern of the active interviewer is striving not to be overly accommodating in seeking information that has yet to be disclosed.

Pressing interviewees to be candid, hoping that they shed light on the "backstage" of performances, is facilitated by a variety of tactics that range from simply "playing dumb" to more challenging and confrontational interview techniques. The active interviewer must be flexible, adaptable, and be prepared to weigh rewards and costs of each approach. From overly aggressive to too accommodating, every strategy has risks that may counteract its benefit and ultimately inhibit the interactive flow.

The literature on active interviewing has been further developed with due reference to the research contributions of scholars emphasizing power dynamics, reflexivity, and positionality in qualitative methods (cf. Song and Parker 1995; Abel et al. 2006; Aléx and Hammarström 2008; Riach 2009). Interview participants are understood to be reciprocally reflexive "in the moment" in a way that 
reflects positionality and dominant discourses that ultimately influence the narratives produced. An adaptive orientation to the task of interviewing necessitates awareness of positioning as fluid, reflecting power relations, social differences, and sameness in ways that manifest in different ways at different times.

Positionalities reflect different social characteristics that shape the form and content of interview exchanges and intersect in ways that are often unpredictable. Shifting positionalities can stimulate disclosure by cultivating commonalities or creating "sticky moments." Exercising reflexivity in interviews can also disrupt the flow and counteract attempts to build rapport. There are benefits to being recognized as an insider and as an outsider (or an "alien observer" whose ignorance invites more detailed talk).

Attempting to wear both hats can be challenging and risky, but might allow the interviewer to have some "cake and eat it too." Research contributions to the literature on active interviewing indicate that dichotomizing the potential role of the insider and outsider oversimplifies the intricate complexity of performing reflexivity and positionality on the part of interviewers. To offer a more nuanced view, we draw on illustrations of active interviewing in two very different studies.

Mostaghim's interviews with students about marijuana use provided opportunities to explore the influence of being both positioned and positioning oneself as an interviewer based on ethnicity and gender, among other characteristics. Identifying as a user and being identified in interviews as an Iranian male graduate student proved advantageous in some situations where these social characteris- tics demonstrated commonality as a (sub)cultural insider. Use of the term "you know" served as a cue for shifting tactics or positionality to a more detached position. Maintaining a non-judgmental tone throughout the interviews appeared to be the common thread facilitating the use of a variety of probes.

Sommers' interviews with city planners and officials benefitted from the fieldwork he conducted in advance. It proved useful in establishing rapport as an insider to probe beyond the "closing off" attempts that he encountered when discussing politically sensitive matters. Showing empathy, as one who knows and understands, or resisting "canned" and sanitized responses were helpful tactics using inside knowledge based on fieldwork experiences to elicit greater candor during interviews. Resisting "you know" type responses required downplaying inside knowledge, and it was at times rejected indicating some resistance by interviewees seeking to (re)assert their authority.

Taken together, these case studies demonstrate the value of adopting a more "active" approach to interviewing. This paper draws attention to the intimate connections between ethnographic fieldwork and other qualitative methods that draw on insights gained from naturalistic observation and being identified as either an insider or outsider. Exercising reflexivity and positionality to foster more insightful conversational dynamics, or resume more fruitful avenues of dialogue, requires a working understanding of associated risks and helpful strategies to overcome them. Building on the academic lineage and legacy of Shaffir's outstanding ethnographic contributions illuminates the crucial role of mentorship and highlights the enduring returns gained by "paying it forward." 


\section{References}

Abell, Jackie et al. 2006. “Trying Similarity, Doing Difference: The Role of Interviewer Self-Disclosure in Interview Talk with Young People." Qualitative Research 6(2):221-244.

Adler, Patricia, Peter Adler, and E. Burke Rochford Jr. 1986. "The Politics of Participation in Field Research." Urban Life 14(4):363-376.

Aléx, Lena and Anne Hammarström. 2008. "Shift in Power during an Interview Situation: Methodological Reflections Inspired by Foucault and Bourdieu." Nursing Inquiry 15(2): 169176.

Atkinson, Paul and Sara Delamont. 2006. "Rescuing Narrative from Qualitative Research.” Narrative Inquiry 16(1):164-172.

Atkinson, Paul and David Silverman. 1997. "Kundera's Immortality: The Interview Society and the Invention of the Self." Qualitative Inquiry 3(3):304-325.

Bauman, Richard and Charles L. Briggs. 1990. "Poetics and Performances as Critical Perspectives on Language and Social Life." Annual Review of Anthropology 19(1):59-88.

Becker, Howard S. 1954. "A Note on Interviewing Tactics." Human Organization 12(winter): 31-32.

Becker, Howard S. 1970. Sociological Work: Method and Substance. Chicago: Aldine.

Berreman, Gerald D. 1962. Behind Many Masks: Ethnography and Impression Management in a Himalayan Village. Ithaca, NY: Society for Applied Anthropology.

Briggs, Charles L. 1986. Learning How to Ask: A Sociolinguistic Appraisal of the Role of the Interview in Social Science Research. New York: Cambridge University Press.

Carey, James T. 1972. "Managing Fronts in Observing Deviance." Pp. 93-115 in Research on Deviance, edited by J. D. Douglas. New York: Random House.

Christie, Robert M. 1976. “Comment on Conflict Methodology: A Protagonist Position.” Sociological Quarterly 17(4):513-519.

Clifford, James and George E. Marcus (eds.). 1986. Writing Culture: The Poetics and Politics of Ethnography. Berkeley, CA: University of California Press.
Day, Suzanne. 2012. "A Reflexive Lens: Exploring Dilemmas of Qualitative Methodology Through the Concept of Reflexivity." Qualitative Sociology Review 8(1):60-85.

Dewalt, Kathleen M. and Billie R. Dewalt. 1998. "Participant Observation." Pp. 259-299 in Handbook of Methods in Cultural Anthropology, edited by H. R. Bernard and G. Ryan. Walnut Creek, CA: Altamira.

Douglas, Jack D. 1985. Creative Interviewing. Vol. 29. Beverly Hills, CA: Sage Publications.

England, Kim V. 1994. “Getting Personal: Reflexivity, Positionality, and Feminist Research." The Professional Geographer 46(1):80-89.

Garfinkel, Harold. 1984. Studies in Ethnomethodology. Cambridge: Polity.

Goffman, Erving. 1959. The Presentation of Self in Everyday Life. Garden City, NY: Doubleday.

Hammersley, Martyn. 2003. “Recent Radical Criticism of Interview Studies: Any Implications for the Sociology of Education?" British Journal of Sociology of Education 24(1):119-126.

Hathaway, Andrew D. and Michael F. Atkinson. 2003. "Active Interview Tactics in Research on Public Deviants: Exploring the Two-Cop Personas." Field Methods 15(2):161-185.

Hathaway, Andrew D. and Michael F. Atkinson. 2005. "Self-Presentation and Social Poetics: Active Interview Tactics in Research with Public Figures." Pp. 66-76 in Doing Ethnography: Studying Everyday Life, edited by D. Pawluch, W. Shaffir, and C. E. Miall. Toronto: Canadian Scholars' Press.

Hathaway, Andrew et al. 2016. "A Nuanced View of Normalisation: Attitudes of Cannabis Non-Users in a Study of Undergraduate Students at Three Canadian Universities." Drugs: Education, Prevention and Policy 23(3):238-246.

Hathaway, Andrew D. et al. 2018. “'It's Really No Big Deal': The Role of Social Supply Networks in Normalizing Use of Cannabis by Students at Canadian Universities." Deviant Behavior 39(12):1672-1680.

Hermanowicz, Joseph C. 2002. “The Great Interview: 25 Strategies for Studying People in Bed." Qualitative Sociology 25(4):479-499. 
Herod, Andrew. 1999. "Reflections on Interviewing Foreign Elites: Praxis, Positionality, Validity, and the Cult of the Insider." Geoforum 30(4):313-327.

Holstein, James A. and Jaber F. Gubrium. 1995. The Active Interview (Vol. 37). London: Sage.

Holstein, James A. and Jaber F. Gubrium. 2016. "Narrative Practice and the Active Interview." Pp. 67-82 in Qualitative Data Analysis, edited by David Silverman. London: Sage.

Keating, Michael. 1993. “The Politics of Economic Development: Political Change and Local Development Policies in the United States, Britain, and France." Urban Affairs Quarterly 28(3):373-396.

Lundman, Richard J. and Paul T. McFarlane. 1974. "Conflict Methodology: An Introduction and Preliminary Assessment." Sociological Quarterly 17(4):503-512.

Mauthner, Natasha S. and Andrea Doucet. 2003. "Reflexive Accounts and Accounts of Reflexivity in Qualitative Data Analysis." Sociology 37(3):413-431.

Miller, J. Mitchell and Richard A. Tewksbury. 2001. Extreme Methods: Innovative Approaches to Social Science Research. Needham Heights, MA: Allyn \& Bacon.

Moss, Pamela. 1995. "Reflections on the 'Gap' as Part of the Politics of Research Design.” Antipode 27(1):82-90.

Mostaghim, Amir H. 2019. “Why Everybody Can't Get Stoned? The Role of Gender and Ethnicity in Mediating the Differentiated Normalisation of Marijuana Use." PhD Dissertation, Department of Sociology \& Anthropology, University of Guelph, Ontario, Canada.

Riach, Kathleen. 2009. “Exploring Participant-Centred Reflexivity in the Research Interview." Sociology 43(2):356-370.

Rice, Gareth. 2010. “Reflections on Interviewing Elites.” Area 42(1):70-75.

Shaffir, William. 1990. "Managing a Convincing Self-Presentation: Some Personal Reflections on Entering the Field." Pp. 72-81 in Experiencing Fieldwork: An Inside View of Qualita- tive Research (Vol. 124), edited by W. Shaffir and R. A. Stebbins. Newbury Park, CA: Sage Publications.

Shaffir, William. 1998. "Doing Ethnographic Research in Jewish Orthodox Communities: The Neglected Role of Sociability." Pp. 48-64 in Doing Ethnographic Research: Fieldwork Settings, edited by S. Grills. Thousand Oaks, CA: Sage Publications.

Shaffir, William. 1999. "Doing Ethnography: Reflections on Finding Your Way." Journal of Contemporary Ethnography 28(6):676-686.

Shaffir, William and Robert A. Stebbins (eds.). 1990. Experiencing Fieldwork: An Inside View of Qualitative Research (Vol. 124). Newbury Park, CA: Sage Publications.

Silverman, David. 2017. "How Was It for You? The Interview Society and the Irresistible Rise of the (Poorly Analyzed) Interview." Qualitative Research 17(2):144-158.

Sommers, Rory. 2016. “Governing Incivility: An Ethnographic Account of Municipal Law Enforcement, Urban Renewal and Neighbourhood Conflict in the City of Hamilton." PhD Dissertation, Department of Sociology \& Anthropology, University of Guelph, Ontario, Canada.

Song, Miri and David Parker. 1995. “Commonality, Difference and the Dynamics of Disclosure in In-Depth Interviewing." Sociology 29(2):241-256.

Spector, Malcolm. 1980. "Learning to Study Public Figures." Pp. 98-109 in Fieldwork Experience: Qualitative Approaches to Social Research, edited by W. Shaffir, R. A. Stebbins, and A. Turowetz. New York: St. Martin's Press.

Weick, Karl E. 2002. “Real Time Reflexivity: Prods to Reflection."Organization Studies 23(6): 893-898.

Weiss, Robert S. 1994. Learning from Strangers: The Art and Method of Qualitative Interview Studies. New York: Free Press.

Young, T. R. 1976. "Some Theoretical Foundations for Conflict Methodology." Sociological Inquiry 46(1):23-29.

\section{Citation}

Hathaway, Andrew D., Rory Sommers, and Amir Mostaghim. 2020. "Active Interview Tactics Revisited: A Multigenerational Perspective." Qualitative Sociology Review 16(2):106-119. Retrieved Month, Year (http://www.qualitativesociologyreview.org/ ENG/archive_eng.php). DOI: http://dx.doi.org/10.18778/1733-8077.16.2.09 